\title{
THE INFLUENCE OF FRICTION STIR WELDED PROCESS PARAMETERS OF AA2519-T62 ON JOINT QUALITY DEFINED BY NON-DESTRUCTIVE LASER AMPLIFIED ULTRASONIC METHOD AND BY MICROSTRUCTURE ANALYSIS
}

\author{
Alexander Kravcov ${ }^{a, *}$, Robert Kosturek ${ }^{b}$, LuCJAn ŚnieżeK $^{b}$, \\ JAnusz KluCzyński $^{b}$, Ondřej FraneK ${ }^{a}$, NikOlaj Morozov ${ }^{a}$, \\ PAWEL MACIEJEWSKI ${ }^{c}$
}

\author{
${ }^{a}$ Czech Technical University in Prague, Faculty of Civil Engineering, Department of Construction Technology, \\ Thákurova 7, 16000 Prague, Czech Republic \\ ${ }^{b}$ Military University of Technology, Faculty of Mechanical Engineering, Institute of Robots Es Machine Design, \\ gen. S. Kaliskiego Street 2, Warsaw, 00-908, Poland \\ ${ }^{c}$ War Studies University, Management and Command Faculty, gen. Antoniego Chruściela "Montera" Street 103, \\ Warsaw, 00-910, Poland \\ * corresponding author: kravtale@fsv.cvut.cz
}

\begin{abstract}
The presented research contains a description of a non-destructive laser ultrasound internal structure analysis of aluminium joints made by friction stir welding. In the research, four selected technological parameter groups were taken into account. Modifications used in different parameter groups included changing tool traverse speeds and also its rotation speeds. The most important goal of this research was to determine the joint quality using a non-destructive laser amplified ultrasound method. To verify obtained test results, an additional microstructural analysis was also conducted.
\end{abstract}

KEYWORDS: Friction Stir Welding, aluminum alloys, microstructure analysis, laser ultrasonic structuroscopy, non-destructive testing.

\section{INTRODUCTION}

FSW (Friction Stir Welding) is a very promising method in terms of joining aluminium alloys, which are difficult to weld using conventional methods [1-4]. This method is a solid-state welding process, where the joint is formed by plasticizing and mixing two workpieces by a specially designed tool [1, 5+7]. An example of an aluminium alloy difficult to weld by conventional means is AA2519 - armour grade alloy used for light military constructions [8, 9. Due to the relatively high concentration of copper (above $5.3 \%$ ), solidification of this alloy in traditional welding causes a problem of low melting phase $\mathrm{Al}_{2} \mathrm{Cu}\left(548^{\circ} \mathrm{C}\right)$ and as a result, a high risk of hot cracking [10 12. Although the low temperature of the FSW process $\left(400-500^{\circ} \mathrm{C}\right)$ allows to avoid this problem, it is still important to properly select welding parameters determining the quality of the obtained joint 13 -16.

It is very important to determine the joint quality not only using destructive but also non-destructive methods to analyse joints right after the process. It is very important to determine the proper joint-quality check method to ensure the required welded material properties. Ultrasound testing methods are useful in determining the internal quality of the material including internal and surface inclusions and defects [17 19]. This method is also useful for analysing material properties by measuring the shear wave velocities [20, 21]. The ability to use a laser to amplify the signal allows the possibility of analysing elements whose thickness is greater than 10 millimetres 22 .

\section{MATERIALS AND METHODS}

The workpiece to be joined was a $5 \mathrm{~mm}$ thick AA2519T62 extrusion with the chemical composition presented in Table 1. The friction stir welding process was performed using the ESAB FSW Legio 4UT machine with an axial force equal to $17 \mathrm{kN}$ and the tilt angle of the MX Triflute tool set to 2o. The used welding parametres, together with a designation of the samples, are presented in Table 2

The joint was analysed along the entire length of the weld and also perpendicularly to the traverse transition direction.

This kind of analysis was made using an optoacoustic equipment and a measuring technique based on the generation of an ultrasonic signal, with ultrashort, high power pulses amplified by a $10-\mathrm{ns} 0.1 \mathrm{~mJ}$ pulse generated by a Nd: YAG laser, which is transmitted to the front side of a special optoacoustic generator (OAG) via an optic fibre cable, an optical beam forming system, and a transparent prism. The OAG is a plane-parallel plate made of ad hoc plastic absorbing light [23].

The transparent prism is in an acoustic contact with the OAG, being at the same time a sound conducting channel of a broadband piezoelectric transducer 


\begin{tabular}{cccccccccccc}
\hline $\mathrm{Fe}$ & $\mathrm{Si}$ & $\mathrm{Cu}$ & $\mathrm{Zn}$ & $\mathrm{Ti}$ & $\mathrm{Mn}$ & $\mathrm{Mg}$ & $\mathrm{Ni}$ & $\mathrm{Zr}$ & $\mathrm{Sc}$ & $\mathrm{V}$ & $\mathrm{Al}$ \\
\hline 0.11 & 0.08 & 0.32 & 0.05 & 0.08 & 0.17 & 0.33 & 0.02 & 0.19 & 0.16 & 0.10 & Base \\
\hline
\end{tabular}

TABLE 1. Chemical composition of AA2519-T62 extrusion.

\begin{tabular}{ccc}
\hline Sample designation & $\begin{array}{c}\text { Tool rotation speed } \\
{[\mathrm{rpm}]}\end{array}$ & $\begin{array}{c}\text { Tool traverse speed } \\
{[\mathrm{mm} / \mathrm{min}]}\end{array}$ \\
\hline T41 & 400 & 100 \\
T81 & 800 & 100 \\
T82 & 800 & 200 \\
T84 & 800 & 400 \\
\hline
\end{tabular}

TABLE 2. Welding parameters and designation of samples.

made of polyvinylidene fluoride (PVDF) film. Oneside access and the acoustic contact are ensured by pressing the OAG plane to the front side of the object with a thin layer of contact fluid in between. The laser pulse absorption by the near-surface layer of the OAG and the subsequent thermal expansion produce an ultrasonic pressure pulse with a known temporal shape and amplitude. The pulse wave propagates through the prism and is recorded by the piezoelectric sensor (direct wave) and towards the sample, where it is partially reflected at the OAG-sample interface due to difference in acoustic impedance; this reflection is recorded by the piezoelectric sensor with the time delay equal to the double travel time in the OAG. The remainder of the pulse energy enters the sample and is scattered by its heterogeneities and reflected from the back side of the sample. In the case of sufficiently strong scattering (which is indicative of a high degree of heterogeneity), the reflection from the back-side may not be observed. Additionally, the samples were sectioned perpendicularly to the welding direction and were metallurgically examined. The microstructure investigation was performed using an Olympus LEXT OLS 4100 digital light microscope. As part of the metallographic sample preparation, samples were mounted in resin, ground with an abrasive paper of $80,320,600,1200$, and 2400 gradations, and polished using diamond pastes ( 3 and $1 \mu \mathrm{m}$ gradation). The samples were etched using the Keller reagent $(20 \mathrm{ml}$ $\mathrm{H}_{2} \mathrm{O}+5 \mathrm{ml} \mathrm{HNO}_{3}+2 \mathrm{ml} \mathrm{HF}+1 \mathrm{~mL} \mathrm{HCl}$ ) with an etching time equal to $5 \mathrm{~s}$.

\section{Results}

The internal structure of the samples is shown in Figure 1. In both samples, where the traverse speed was $100 \mathrm{~mm} / \mathrm{min}$ (T41 \& T81), some imperfections can be observed, they appear as different coloured structures and wave shape distortions. This could also be connected with the density change, which is caused by the welding process. As can be seen, the wave shape distortions are present in the samples obtained with the lowest tool traverse speed, which entails the longest affecting time of the tool on the welded AA2519-T62.
This leads to phenomena, such as substantial dissolution and coarsening of the strengthening phase and fragmentation of the remaining $\mathrm{Al}_{2} \mathrm{Cu}$ precipitates in the stir zone, and it can partly explain the wave distortions in Figure 1 [14.

In the course of scanning, local velocities are determined. The velocities dependent on density are related to local modules of elasticity; they can be calculated as follows:

$$
\begin{gathered}
E=\rho C_{t}^{2}\left[3-\frac{1}{x^{2}-1}\right] \\
G=\rho C_{t}^{2}
\end{gathered}
$$

where: $E$ is Young's modulus, $G$ is shear modulus. Note that an S-wave pulse is recorded in the interval between the first and second reflections of $\mathrm{P}$-waves from the back side; the time delay of the S-wave's arrival can be used to calculate its velocity.

Density was determined by hydrostatic weighing of the samples in distilled water. The mean density of the AA2519 alloy is $\rho=2820000 \mathrm{~kg} \cdot \mathrm{m}^{-3}$. The average obtained values of the elastic moduli for the aluminium alloy were $E=67.5 \mathrm{GPa}$ and $G=28.5 \mathrm{GPa}$.

Zones of recrystallization and thermomechanical affection relative to the base material are distinctly distinguishable in the analysis. During the scan, it was found that the elastic modules in the thermomechanically affected zone and the recrystallization zone are reduced by $15 \%$, relative to the base material. The changes in elastic modules in these areas can be explained by far-reaching changes in the welded material microstructure.

The mechanical properties of AA2519 are mostly determined by the presence of the strengthening phase. During the FSW process, this phase undergoes disadvantageous evolutions mostly in the recrystallization zone and thermo-mechanically affected zone [1, 4.

To verify the results from the ultrasound method, light microscope observations were performed. The macrostructure of the T81 joint is presented in Figure 2 with the retreating and advancing side situated on the right and left side, respectively. The macrostructure consists of zones typical for the FSW 

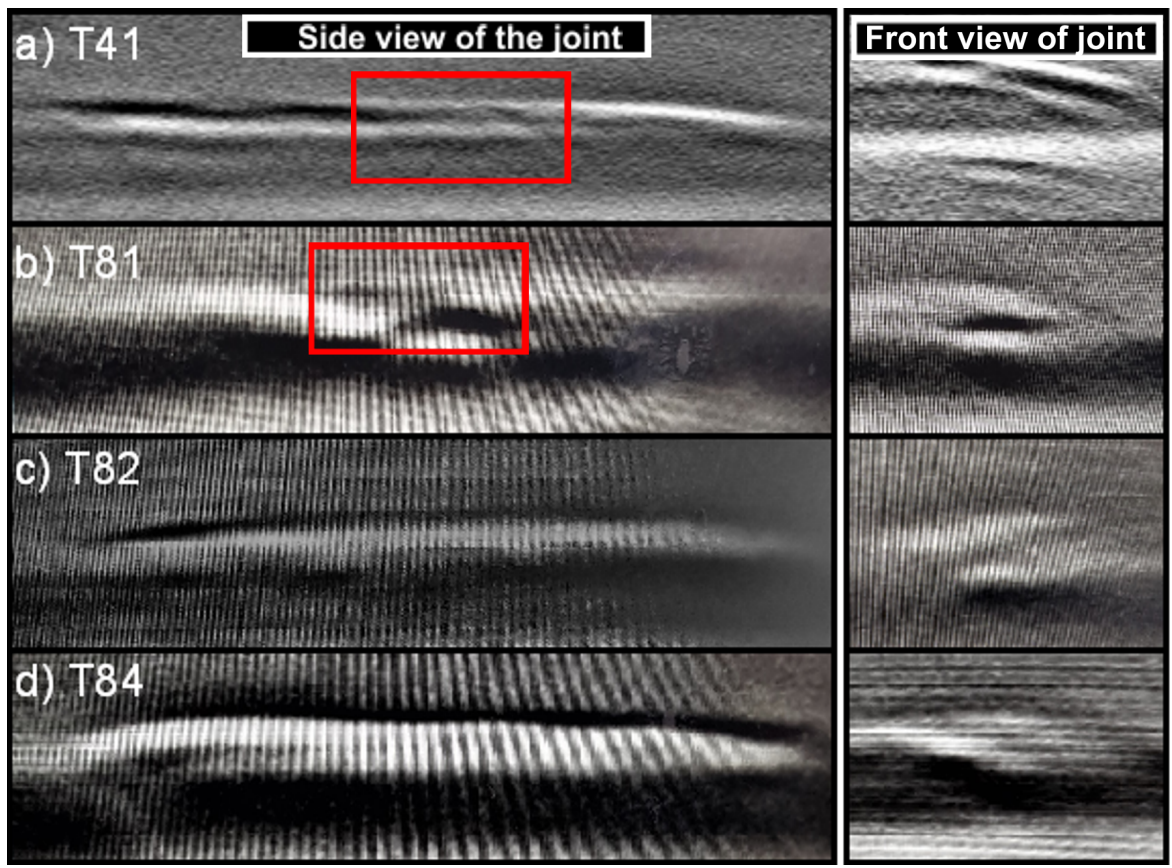

FiguRE 1. Internal structure of FSW samples: (a) imperfection in the middle of the T41 joint (red box) - material density change, (b) imperfection in the middle of the T81 joint (red box) - voids and material density change, (c) regular structure of the T82 joint stir zone, (d) regular structure of the T84 joint stir zone.

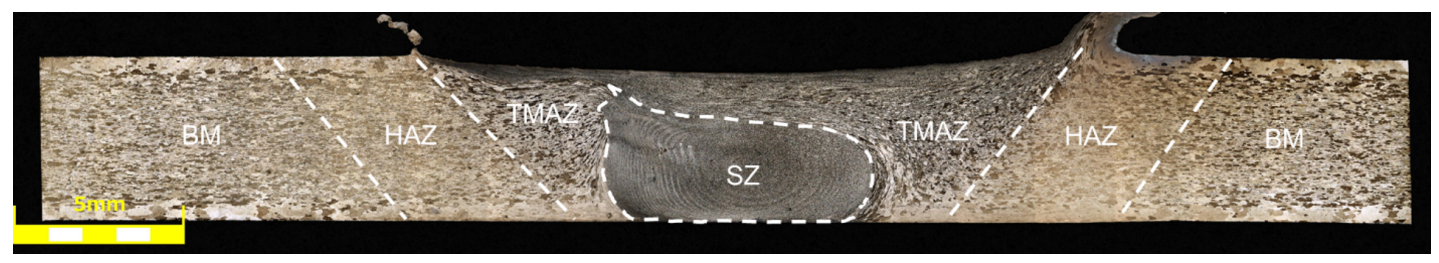

FiguRE 2. Macrostructure of T81 joint.

process: the dynamically recrystallized stir zone (SZ), thermo-mechanically affected zone (TMAZ), heataffected zone (HAZ) and base material (BM). The microstructure analysis of the T81 sample did not reveal any imperfections in the joint. At the same time, in samples T41, T82 and T84, the light microscopy observations allowed to identify the imperfections, which are presented in Figure 3

In the case of the T41 sample, the low value of the tool rotation speed $(400 \mathrm{rpm})$ caused the formation of imperfections close to the flash on the advancing side of the joint as a result of insufficient material plasticization (Figure 3a). The investigation of the T82 and T84 samples revealed imperfections in the form of voids localised in the upper part of the stir zone (Figure 3c 3d). The number of voids increases together with the increasing tool traverse speed value. As can be observed, the same area in the T81 sample is characterized by a lack of visible voids (Figure 3d). Higher values of the tool traverse speed result in a decrease of the time in which the tool affects the workpiece by friction, which can cause the presence of imperfections in the joint. It is a noteworthy fact that all imperfections identified by microstructure analysis, are localised on the advancing side of the joints, which corresponds to a lower heat input than that of the retreating side. Although insufficient heat input is the main reason for the low joint quality, the character of the imperfections differs depending on the welding parameters.

\section{Conclusion}

This research presents the results from the performed microstructural analysis. The results present possibilities to inspect the technology of friction stir welding with the help of laser-ultrasonic structuroscopy and diagnose the presence of continuity defects. A method for determining Young's modulus and shear modulus is presented. The study showed that the decrease in the value of the elastic moduli of the recrystallization region and thermo-mechanically affected zone was, on average, $15 \%$.

During the analysis of the microstructure, it was determined that high values of tool traverse speed lead to the appearance of defects in the joint. Most of the specific defects are localised on the advancing side of the joint. 


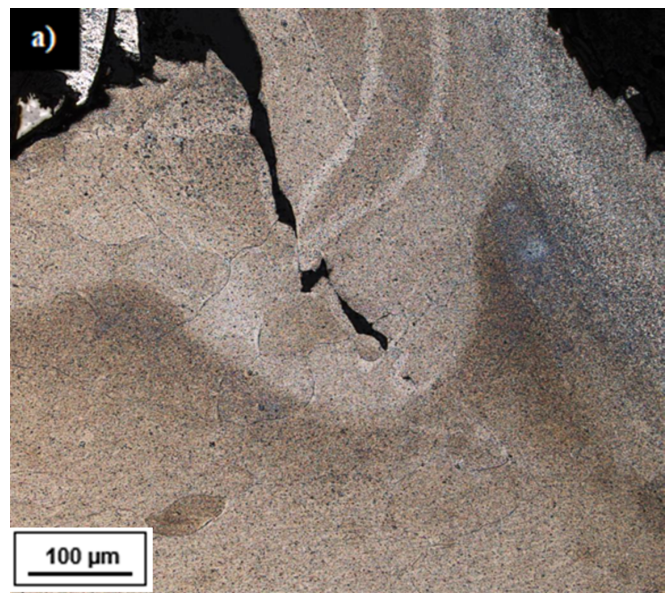

(A).

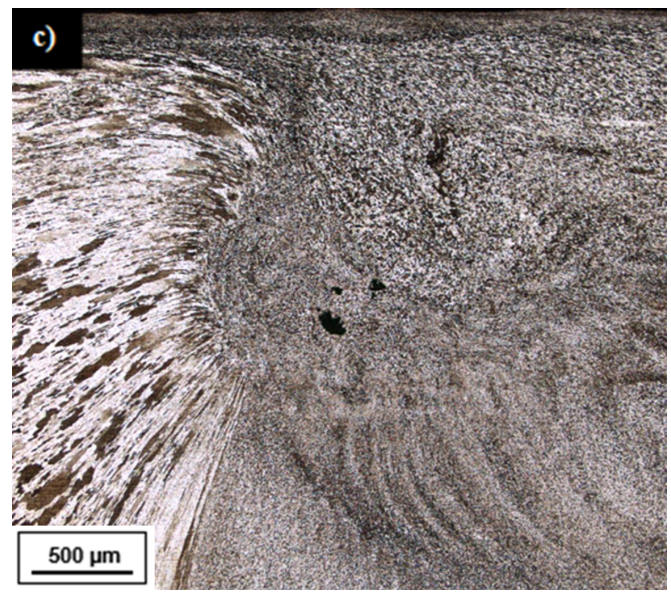

(c).

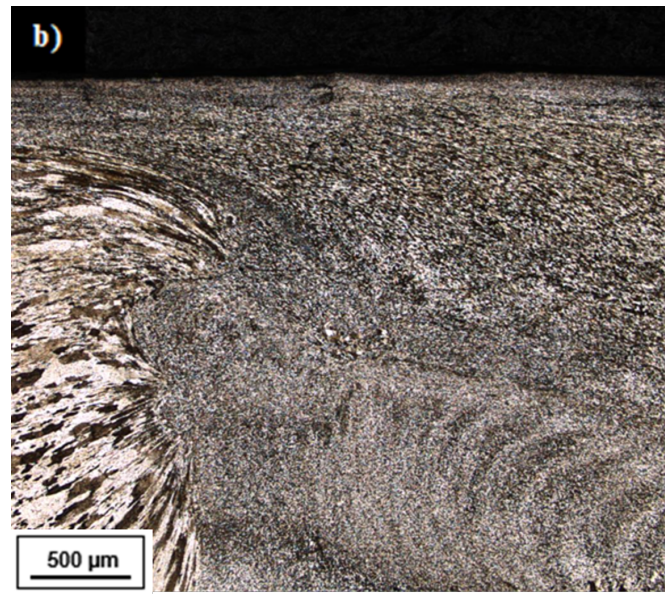

(в).

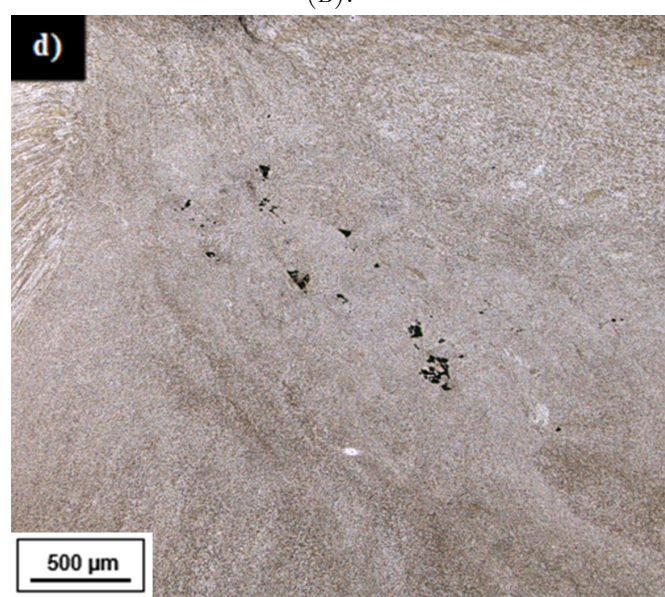

(D).

FigURE 3. Microstructure of: (a) imperfection close to the flash in the T41 joint, (b) imperfection-free upper part of the T81 joint stir zone, (c) voids in the upper part of the T82 joint stir zone, (d) voids in the upper part of the T84 joint stir zone.

\section{ACKNOWLEDGEMENTS}

This research was financially supported by the National Ministry of Education of Czech Republic (No. 027/0008465). In addition, authors would like to acknowledge the financial support from the Polish Ministry of National Defence (No. PBG/13-998). The authors would also want to thank Lt.Col. Dr. Ing. Paweł Maciejewski (War Studies Academy) and the Czech Technical University.

\section{REFERENCES}

[1] R. S. Mishra, M. W. Mahoney. Friction Stir Welding and Processing. ASM International: Materials Park, 2007.

[2] C. Venkata Rao, G. Madhusudhan Reddy, K. Srinivasa Rao. Microstructure and pitting corrosion resistance of AA2219 Al-Cu alloy friction stir welds effect of tool profile. Defence Technology 11(2):123 131, 2015. DOI:10.1016/j.dt.2014.10.003.

[3] S. Babu, K. Elangovan, V. Balasubramanian, M. Balasubramanian. Optimizing friction stir welding parameters to maximize tensile strength of AA2219 aluminum alloy joints. Metals and Materials
International 15:321 - 330, 2009. DOI:10.1007/s12540-009-0321-3.

[4] S. Sree Sabari, S. Malarvizhi, V. Balasubramanian. Characteristics of FSW and UWFSW joints of AA2519-T87 aluminium alloy: Effect of tool rotation speed. Journal of Manufacturing Processes 22:278 289, 2016. DOI:10.1016/j.jmapro.2016.03.014

[5] R. Kosturek, M. Wachowski, T. Ślęzak, et al. Research on the friction stir welding of titanium grade 1. In Proceedings of the International Conference on Advanced Functional Materials and Composites (ICAFMC2018), vol. 242. MATEC Web of Conferences, 2018. DOI:10.1051/matecconf/201824201006.

[6] Z. Zhang, B. L. Xiao, Z. Y. Ma. Effect of welding parameters on microstructure and mechanical properties of friction stir welded 2219al-t6 joints. Journal of Materials Science 47:4075 - 4086, 2012. DOI:10.1007/s10853-012-6261-1.

[7] X.-P. Liang, H.-Z. Li, Z. Li, et al. Study on the microstructure in a friction stir welded 2519-T87 Al alloy. Materials \& Design 35:603 - 608, 2012. DOI:10.1016/j.matdes.2011.10.009 
[8] J. Fisher, J. James. Aluminum alloy 2519 in military vehicles. Advanced Materials \& Processes 160:43 - 46, 2002 .

[9] Y.-P. Wu, L.-Y. Ye, Y.-Z. Jia, et al. Precipitation kinetics of 2519A aluminum alloy based on aging curves and DSC analysis. Transactions of Nonferrous Metals Society of China 24(10):3076 - 3083, 2014. DOI:10.1016/S1003-6326(14)63445-2

[10] G. B. Schaffer, T. B. Sercombe, R. N. Lumley. Liquid phase sintering of aluminium alloys. Materials Chemistry and Physics 67(1):85 - 91, 2001. DOI:10.1016/S0254-0584(00)00424-7

[11] N. V. Stoichev, S. B. Yaneva, L. L. Regel, I. V. Videnskiy. Eutectic solidification of $\mathrm{Al}-\mathrm{Cu}$ alloys influenced by convection. Advances in Space Research 8(12): $171-174,1988$. DOI:10.1016/0273-1177(88)90020-8

[12] M. Gündüz, E. Çadırlı. Directional solidification of aluminium-copper alloys. Materials Science and Engineering: A 327(2):167 - 185, 2002. DOI:10.1016/S0921-5093(01)01649-5

[13] W. F. Xu, J. H. Liu, D. L. Chen, G. H. Luan. Low-cycle fatigue of a friction stir welded 2219-T62 aluminum alloy at different welding parameters and cooling conditions. International Journal of Advanced Manufacturing Technology 74:209 - 218, 2014. DOI:10.1007/s00170-014-5988-z

[14] R. Kosturek, L. Sniezek, M. Wachowski, J. Torzewski. The influence of post-weld heat treatment on the microstructure and fatigue properties of sc-modified AA2519 friction stir-welded joint. Materials 12:583, 2019. DOI:10.3390/ma12040583

[15] R. Kosturek, L. Sniezek, J. Torzewski, M. Wachowski. Research on the friction stir welding of Sc-modified AA2519 extrusion. Metals 9:1024, 2019. DOI: $10.3390 /$ met9101024

[16] A. Kravcov, P. Svoboda, J. Štoller, et al. Development of innovative solutions for intelligent inspection of products of additive manufacturing for navy supply, challenges to national defence in contemporary geopolitical situation. The General Jonas Žemaitis Military Academy of Lithuania 2020.
[17] J. Štoller, E. Zezulová. Use of ultrasound — The ultrasonic pulse velocity method for the diagnosis of protective structures after the load of TNT explosion. In ICMT 2017 - 6th International Conference on Military Technologies, pp. 230 - 235. 2017. DOI:10.1109/MILTECHS.2017.7988761.

[18] P. Svoboda, A. Kravcov, V. Pospichal, et al. Quality assessment of bored pile foundations by a set of nondestructive testing methods. In ICMT 2019 - 6th International Conference on Military Technologies, pp. 1 - 4. 2019. DOI:10.1109/MILTECHS.2019.8870062

[19] J. Štoller, P. Dvořák. Ultrasound diagnosis of protective structures after contact explosion. In Transport Means 2014, pp. 264 - 267. Kaunas University of Technology, Lithuania, 2014.

[20] J. Kluczyński, L. Śnieżek, A. Kravcov, et al. The examination of restrained joints created in the process of multi-material FFF additive manufacturing technology. Materials 13(4):903, 2020. DOI:10.3390/ma13040903

[21] R. Quintero, F. Simonetti, P. Howard, et al. Noncontact laser ultrasonic inspection of ceramic matrix composites (CMCs). NDT \& E International 88:8 - 16, 2017. DOI:10.1016/j.ndteint.2017.02.008

[22] A. Kravcov, I. Shibaev. Examination of structural members of aerial vehicles by laser ultrasonic structuroscopy. International Journal of Civil Engineering and Technology 9(11):2258 - 2265, 2018.

[23] A. Kravcov, P. Platek, W. Koperski, V. Pospíchal. Internal structure research of $3 \mathrm{D}$ printed cellular structures by laser-ultrasonic structuroscopy. In 2019 International Conference on Military Technologies (ICMT), pp. 1 - 7. 2019. DOI:10.1109/MILTECHS.2019.8870047. 